\title{
Seal it to Heal it-Management of Side Branch Perforation with Autologous Clotted Blood
}

\author{
S Mehrotra* and R Vijayvergiya \\ Department of Cardiology, Postgraduate Institute of Medical Education and Research, India
}

Submission: September 01, 2017; Published: September 14, 2017

*Corresponding author:S Mehrotra, Associate Professor, Department of Cardiology, Postgraduate Institute of Medical Education and Research,

3rd Floor, C block, Faculty Room, ACC, Chandigarh, India, Email: rhythm_divine46@yahoo.com

\section{Abstract}

Coronary perforations (CP) are rare but feared complications of coronary interventions [1-4]. Treatment of guidewire-induced CP (GW-CP) is challenging because they may be associated with catastrophic clinical consequences if unsuspected or poorly managed. We report a patient whose intervention was complicated by coronary perforation due to balloon inflation in a small branch of the left cirumflex coronary artery (LCX). Blood extravastion to the pericardium was stopped by embolisation of the artery with patients own blood, thereby avoiding the need for emergent cardiac surgery.

Keywords: Coronary perforation; Dual catheter technique; Autologous clotted blood

\section{Presentation of the Case}

60-year-old hypertensive male had presented with recent onset NYHA class II angina. The electrocardiogram (ECG) showed ST depression and T wave inversion in leads V1-V4. The 2-D echocardiogram revealed normal LVEF (60\%) with no wall motion abnormality. Coronary angiography revealed a tight 90\% stenosis in Mid LAD (Left anterior descending) and a total occlusion of proximal LCX (Figure 1). The patient underwent PCI after an informed consent. The patient was given $600 \mathrm{mg}$ clopidogrel one day prior and 5,000U intravenous heparin was given at the start of the procedure. According to the clinical setting and electrocardiogram changes, LAD was considered to be the culprit vessel with CTO (chronic total occlusion) of LCX. The left main was engaged with 6 Fr EBU 3 (Cordis Co., USA) and PCI (percutaneous coronary intervention) of LAD was performed with a DES (drug eluting stent) with good angiographic result. The LCX occlusion was crossed with Sion Blue wire (Asahi Intecc Co., Japan). The wire however slipped into one of the small side branches which was mistaken to be the main vessel. Predilatation with wire in a small branch with a $2.5 \mathrm{X} 12 \mathrm{~mm}$, Emerge, (Boston Scientific, Natick, MA) (Figure 2) resulted in a grade III C.P (Figure 3). Mechanical hemostasis was accomplished by inflating the same predilatation balloon in the main branch proximal to the perforation. Multiple inflations were performed at low atmospheres for $4-5 \mathrm{~min}$. However extravasation of contrast medium to the pericardium persisted necessitating reversal of heparin by administering $5 \mathrm{mg}$ of Protamine. The leaking LCX branch had to be now targeted for occlusive treatment and for which intra-coronary injection of autologous clotted blood was considered, as other embolic materials like gel foam, collagen and coils were not available on the shelf.

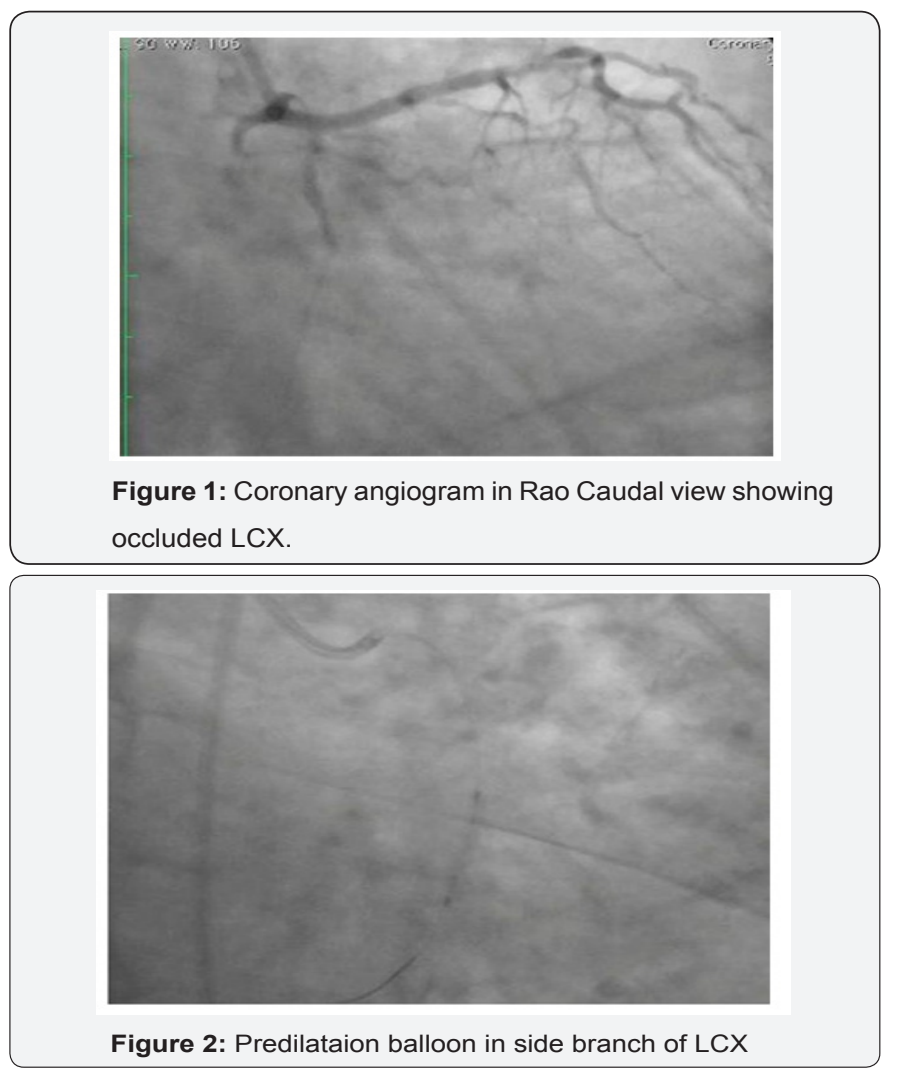




\section{Juniper Online Journal of Case Studies}

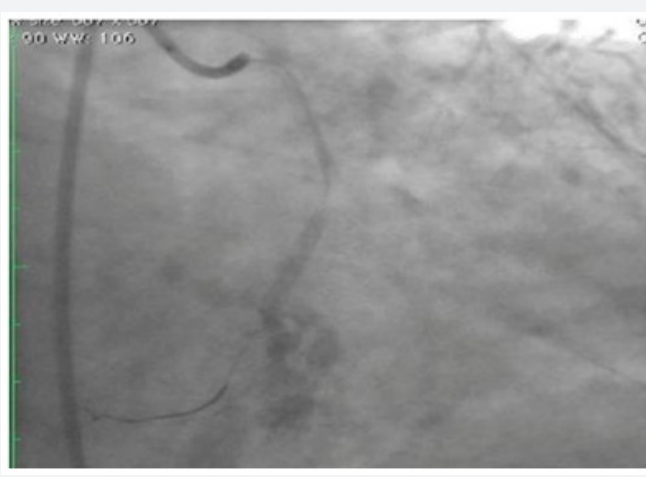

Figure 3: Grade III coronary perforation.

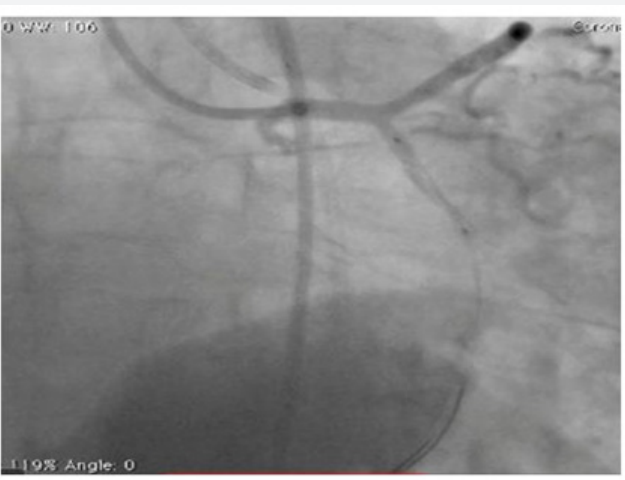

Figure 4: Dual catheter technique to achieve embolization of leaking vessel.

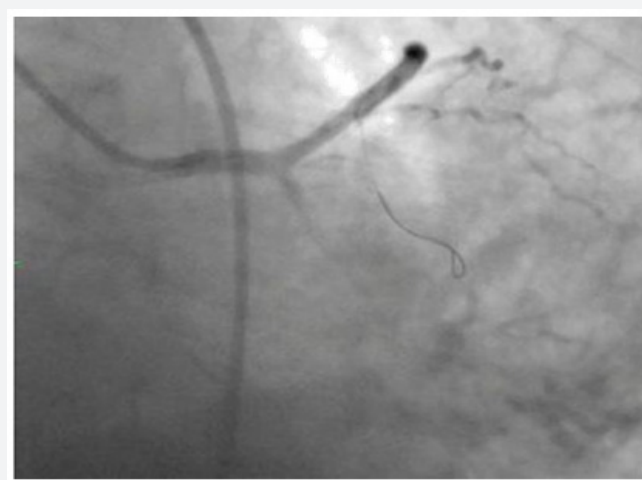

Figure 5: Proximal LCX occluded by autologous blood.

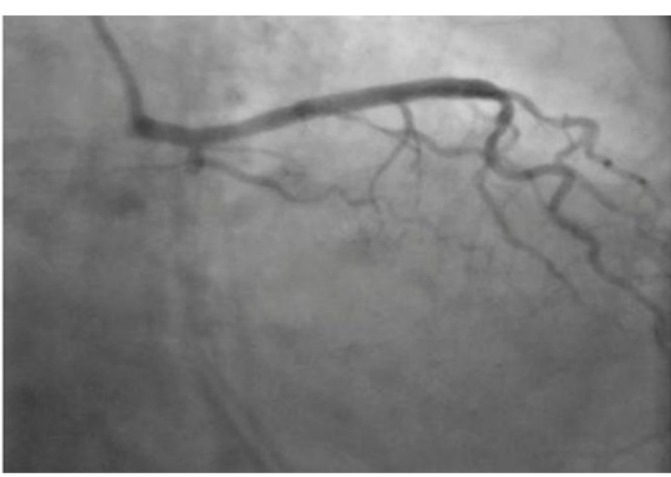

Figure 6: Check angioram showing occluded LCX

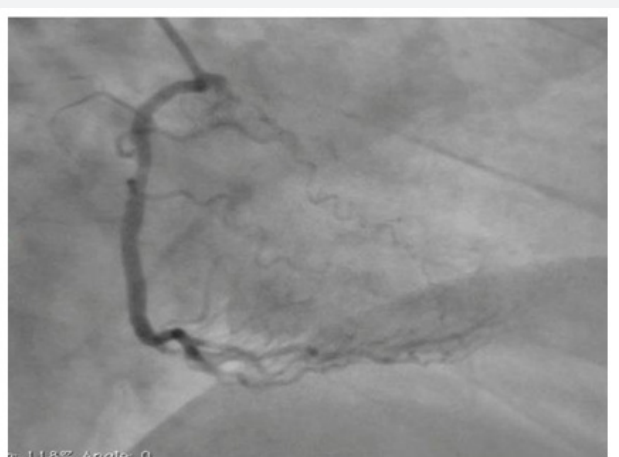

Figure 7: RCA angiogram to demonstrate absence of leak from collateral supply to occluded LCX.

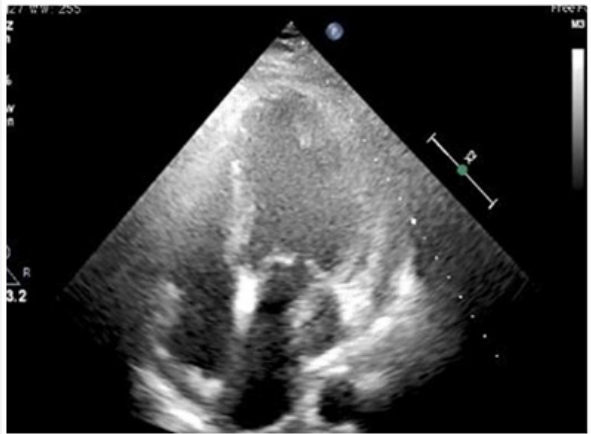

Figure 8: 2D Echocardiography showing mild pericardial effusion.

To decrease extravasation time during autologous blood embolisation, the left common femoral artery was accessed with a $6 \mathrm{Fr}$ sheath and a 6Fr EBU 3 guide catheter was advanced and placed adjacent to the 6Fr guide catheter at the LM ostium (Figure 4). This sequence of events was performed in approximately $4 \mathrm{~min}$ and prevented the development of tamponade. A sion blue wire was then passed into the distal LCX with transient balloon deflation to allow wire passage. Autologous clotted blood injected through the aspiration thrombectomy (Pronto LP, Vascular Solutions, Minneapolis, MN) catheter was used to embolise the leaking vessel. The balloon was kept inflated during injection of clotted blood to prevent back leak. The LCX artery occluded instantaneously at proximal level with immediate stoppage of the leak into the pericardium .There was an excellent final result (Figure 5) and the absence of extravasation was confirmed in a repeat angiography (Figure 6). RCA (right coronary artery) angiogram was also taken (Figure 7) which did not reveal any leak from the collateral supply to the occluded LCX. The ECG showed $Q$ waves in I, AVL and troponin values were positive. The following morning, the echocardiogram showed mild pericardial and pleural effusion (Figure 8) and the patient was discharged at $72 \mathrm{hrs}$ with a subsequent uneventful course.

\section{Discussion}

The frequency of coronary perforation ranges from $0.19 \%$ to $3.0 \%[2,5-8], 0.1 \%$ in balloon angioplasty and $0.5-3 \%$ in procedures involving the so called newer devices. Risk factors 


\section{Juniper Online Journal of Case Studies}

for perforation include complex coronary anatomy (Type B2 and C lesions), chronic total occlusion, rotational atherectomy and intravascular ultrasound use [3]. The in-hospital outcome after perforations is complicated by death in about $10 \%$, myocardial infarction in 19\%-34\% and emergency surgery in 12\%-39\% [9]. Vessel occlusion, intramyocardial hemorrhage, and the development of cardiac tamponade, mainly determine the clinical outcome in patients with coronary perforation

Therapeutic measures for management depends on the type of perforation as well as its location. A perforation in the proximal part of a vessel can be managed with prolonged balloon inflation $[1,10]$ or with the deployment of covered stent, provided there is no side branch at the site of perforation. However in a location at a distal segment or branch of a vessel as in the index case, in addition to prolonged balloon inflation, embolization of the leaking vessel is the therapeutic goal to stop the leak at the cost of inducing an iatrogenic infarction. There are several reports describing the usefulness of subcutaneous fat, coils, gel foam and thrombin for the treatment of side branch perforation [1114]. However, there are few reports describing the treatment of side branch perforation as in the present case with autologous clotted [15-17] blood.

Autologous blood clot is made by stirring blood gathered from the sheath and when left to stand, the clot is easily divided into a hard thrombus and fragile thrombus. The time required for the blood to become of thick consistency was approximately 15 minutes, and was probably related to the anticoagulation level at that time. The advantage of autologous clotted blood over other agents is that it is safe, cost effective and can be obtained easily. Most importantly, unlike other agents, embolization with clotted blood is reversible and salvages the target organ [18]. The occlusion of the lumen of the vessel is unstable and easily disrupted allowing perfusion, but the clot adherent to the vessel wall remains stable, thus preventing any leak. However as the leak in our case was from a small side branch into the pericardium, disruption of intraluminal clot to maintain vessel patency was not attempted. One disadvantage is that since blood clot is formed outside the body, it may cause infection if stringent sterile precautions are not exercised during its preparation. Another concern is the risk of systemic embolization.

\section{Conclusion}

Autologous clotted blood embolization of the leaking vessel represents an alternate way to attempt nonsurgical management of coronary perforation especially in cases where the guidewire cannot be advanced beyond the site of perforation and in small vessels where prolonged balloon inflation fails and deployment of covered stent is not an option.

\section{References}

1. Ellis SG, Ajluni S, Arnold AZ, Popma JJ, Bittl JA, et al. (1994) Increased coronary perforation in the new device era. Incidence, classification, management, and outcome. Circulation 90(6): 2725-2730.

2. Shimony A, Zahger D, Van Straten M, Shalev A, Gilutz H, et al. (2009) Incidence, risk factors, management and outcomes of coronary perforation during percutaneous coronary intervention. Am J Cardiol 104(12): 1674-1677.

3. Al-Lamee R, Ielasi A, Latib A, Godino C, Ferraro M, et al. (2011) Incidence, predictors, management, immediate and long-term outcomes following grade III coronary perforation. JACC Cardiovasc Interv 4(1): 87-95.

4. Wong CM, Kwong Mak GY, Chung DT (1998) Distal coronary artery perforation resulting from the use of hydrophilic coated guidewire in tortuous vessels. Cathet Cardiovasc Diagn 44(1): 93-96.

5. Fasseas P, Orford JL, Panetta CJ, Bell MR, Denktas AE, et al. (2004) Incidence, correlates, management, and clinical outcome of coronary perforation: Analysis of 16,298 procedures. Am Heart J 147(1): 140145.

6. Ramana RK, Arab D, Joyal D, Steen L, Chol L, et al. (2005) Coronary artery perforation during percutaneous coronary intervention: incidence and outcomes in the new interventional era. J Invasive Cardiol 17(11): 603-605.

7. Shirakabe A, Takano H, Nakamura S, Kikuchi A, Sasaki A, et al. (2007) Coronary perforation during percutaneous coronary intervention. Int Heart J 48(1): 1-9.

8. Doll JA, Nikolsky E, Stone GW, Mehran R, Lincoff AM, et al. (2009) Outcomes of patients with coronary artery perforation complicating percutaneous coronary intervention and correlations with the type of adjunctive antithrombotic therapy: Pooled analysis from REPLACE-2, ACUITY, and HORIZONS-AMI trials. J Interv Cardiol 22(5): 453-459.

9. Storger H (2002) Incidence, Prevention, and Treatment of Vascular Perforations Complicating Coronary Interventions .Journal of Interventional Cardiology 15(6): 505-510.

10. Ajluni SC, Glazier S, Blankenship L, O'Neil WW, Safian RD (1994) Perforations after percutaneous coronary interventions: Clinical, angiographic, and therapeutic observations. Cathet Cardiovasc Diagn 32(3): 206-212.

11. Aslam MS, Messersmith RN, Gilbert J, Lakier JB (2000) Successful management of coronary artery perforation with helical platinum microcoil embolization. Cathet Cardiovasc Intervent 51(3): 320-322.

12. Gaxiola E, Browne KF (1998) Coronary artery perforation repair using microcoil embolization. Cathet Cardiovasc Interv 43(4): 474-476.

13. Jamali AH, Lee MS, Makkar RR (2006) Coronary perforation after percutaneous coronary intervention successfully treated with local thrombin injection. J Invasive Cardiol 18(4): E143-E145.

14. Oda H, Oda M, Makiyama Y, Kashimura T, Takahashi K, et al. (2005) Guidewire-induced coronary artery perforation treated with transcatheter delivery of subcutaneous tissue. Catheter Cardiovasc Interv 66(3): 369-374.

15. Cordero H, Gupta N, Underwood PL, Gogte ST, Heuser RR (2001) Intracoronary autologous blood to seal a coronary perforation. Herz 26(2): 157-160.

16. Hadjimiltiades S, Paraskevaides S, Kazinakis G, Louridas G (1998) Coronary vessel perforation during balloon angioplasty: a case report. Cathet Cardiovasc Diagn 45(4): 417-420.

17. Tanaka S, Nishigaki K, Ojio S, Yasuda S, Okubo M, et al. (2008) Transcatheter embolization by autologous blood clot is useful management for small side branch perforation due to percutaneous coronary intervention guide wire. J Cardiol 52(3): 285-289.

18. Gunji T, Kawauchi N, Akahane M, Watanabe K, Kanamori H, et al. (2002) Long term outcomes of transcatheter arterial chemoembolization with autologous blood clot for unresectable hepatocellular carcinoma . Int J Oncol 21(2): 427-432. 
Your next submission with Juniper Publishers will reach you the below assets

- Quality Editorial service

- Swift Peer Review

- Reprints availability

- E-prints Service

- Manuscript Podcast for convenient understanding

- Global attainment for your research

- Manuscript accessibility in different formats

( Pdf, E-pub, Full Text, Audio)

- Unceasing customer service

Track the below URL for one-step submission https://juniperpublishers.com/online-submission.php 